\title{
Optical second-order nonlinearity of poled borosilicate glass containing $\mathrm{CuCl}$
}

\section{AUTHOR(S):}

Sasai, Jun; Tanaka, Katsuhisa; Hirao, Kazuyuki

\section{CITATION:}

Sasai, Jun ...[et al]. Optical second-order nonlinearity of poled borosilicate glass containing CUCl. JOURNAL OF APPLIED PHYSICS 2000, 88(5): 2200-2204

\section{ISSUE DATE:}

2000-09-01

URL:

http://hdl.handle.net/2433/39695

\section{RIGHT:}

Copyright 2000 American Institute of Physics. This article may be downloaded for personal use only. Any other use requires prior permission of the author and the American Institute of Physics. 


\title{
Optical second-order nonlinearity of poled borosilicate glass containing $\mathrm{CuCl}$
}

\author{
Jun Sasai ${ }^{\mathrm{a})}$ \\ Department of Material Chemistry, Graduate School of Engineering, Kyoto University, Sakyo-ku, \\ Kyoto, 606-8501, Japan \\ Katsuhisa Tanaka \\ Department of Chemistry and Materials Technology, Faculty of Engineering and Design, \\ Kyoto Institute of Technology, Sakyo-ku, Kyoto, 606-8585, Japan \\ Kazuyuki Hirao \\ Department of Material Chemistry, Graduate School of Engineering, Kyoto University, Sakyo-ku, \\ Kyoto, 606-8501, Japan
}

(Received 10 February 2000; accepted for publication 5 June 2000)

\begin{abstract}
The effect of surface etching on second-harmonic (SH) intensity and Maker fringe pattern have been examined for poled borosilicate glasses containing $\mathrm{CuCl}$. A drastic decrease in the $\mathrm{SH}$ intensity was observed with anode-side surface etching, while such a decrease did not appear when the cathode-side surface etching was carried out. However, after $20 \mu \mathrm{m}$ etching of the anode-side surface, a decrease in SH intensity with the cathode-side etching was observed. For some samples, the theoretical Maker fringe pattern derived on the assumption that the SH wave is generated from a thin layer near the anode-side surface is in good agreement with the experimental one. On the other hand, other samples show oscillation in the fringe, which originates from the interference of SH waves generated from both surfaces. These results suggest that the nonlinear layer is present at both surfaces, although it is much weaker near the cathode. It is thought that the origin of the nonlinearity is attributable to migration of $\mathrm{Cu}^{+}$and $\mathrm{Cl}^{-}$. (C) 2000 American Institute of Physics. [S0021-8979(00)01218-4]
\end{abstract}

\section{INTRODUCTION}

Second-harmonic generation (SHG), a second-order nonlinear optical process, is basically forbidden in optically isotropic materials like glasses because they have inversion symmetry. Nonetheless, SHG can be observed in glass-based materials when additional treatment is done so that they possess noncentrosymmetry. One effective treatment is poling. Since the successful observation of SHG in thermally poled silica glass, ${ }^{1}$ vigorous studies have been executed to deduce the mechanism of SHG in poled glasses. As for the poled silica glasses, it was suggested that the migration of charged ions such as $\mathrm{Na}^{+}, \mathrm{H}^{+}$, and $\mathrm{OH}^{-}$forms a large dc electric field, leading to a lack of inversion symmetry. ${ }^{1-4}$ Another method to induce second-order nonlinearity in glass materials is to utilize precipitation of crystals which do not have inversion symmetry. ${ }^{5-8}$ In this case, a second-harmonic ( $\left.\mathrm{SH}\right)$ wave is generated from the crystals precipitated. In particular, orientation of the lattice plane which corresponds to the largest component of the second-order nonlinear susceptibility tensor is preferable.

It is known that $\mathrm{CuX}(\mathrm{X}=\mathrm{Cl}, \mathrm{Br}, \mathrm{I})$ containing glasses show high ionic conductivity due to the large mobility of $\mathrm{Cu}^{+} .{ }^{9}$ Since the initial stage to induce SHG in glass is the migration of mobile ions as mentioned above, $\mathrm{Cu}^{+}$-ion conduction feasibly contributes to the formation of internal dc electric field. In addition, CuX crystals exhibit second-order

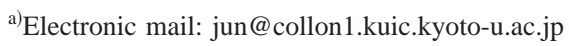

nonlinearity because they do not possess inversion symmetry. ${ }^{10-13}$ Considering that SHG was observed in CdSe, which is a noncentrosymmetric crystal, even though the size of the crystal was very small, ${ }^{14}$ glass ceramics containing $\mathrm{CuX}$ microcrystals possibly show second-order nonlinearity. From both viewpoints, second-order nonlinear properties of $\mathrm{CuX}$-containing glasses are interesting.

In a previous paper, ${ }^{18}$ we reported the enhancement of $\mathrm{SH}$ intensity by addition of $\mathrm{CuCl}$ in poled glass. We speculated that the origin of the enhancement was due to the migration of $\mathrm{Cu}^{+}$in glass during poling. In the present investigation, we report the effect of surface etching on $\mathrm{SH}$ intensity and the Maker fringe pattern and examine the origin of noncentrosymmetry induced by poling.

\section{EXPERIMENTAL PROCEDURES}

Glass with $63 \mathrm{SiO}_{2} \cdot 17 \mathrm{~B}_{2} \mathrm{O}_{3} \cdot 4 \mathrm{Li}_{2} \mathrm{O} \cdot 4 \mathrm{~K}_{2} \mathrm{O} \cdot 2.3 \mathrm{Na}_{2} \mathrm{O}$ - $4.7 \mathrm{NaCl} \cdot 4.6 \mathrm{Al}_{2} \mathrm{O}_{3} \cdot 3 \mathrm{ZrO}_{2} \cdot 0.5 \mathrm{SnO}_{2} \cdot 1 \mathrm{CuCl}(\mathrm{mol} \%)$ composition was prepared by melting raw materials in a platinum crucible at $1500{ }^{\circ} \mathrm{C}$ for $1.5 \mathrm{~h}$. The melt was quenched and the glass thus obtained was cut into a plate $12 \mathrm{~mm} \times 12 \mathrm{~mm} \times 1$ $\mathrm{mm}$. The glass surfaces were polished with sandpaper and $\mathrm{CeO}_{2}$ powder. Then, the glass was heat treated at $550{ }^{\circ} \mathrm{C}$ for $2 \mathrm{~h}$. Via this heat treatment, precipitation of $\mathrm{CuCl}$ nanocrystals occurred. ${ }^{15}$ Thermal poling was carried out at $300^{\circ} \mathrm{C}$ with a voltage of $3 \mathrm{kV}$ applied for $3 \mathrm{~h}$.

Optical absorption spectra were measured by a spectrophotometer (Hitachi 330) for poled glass (see Fig. 1). 


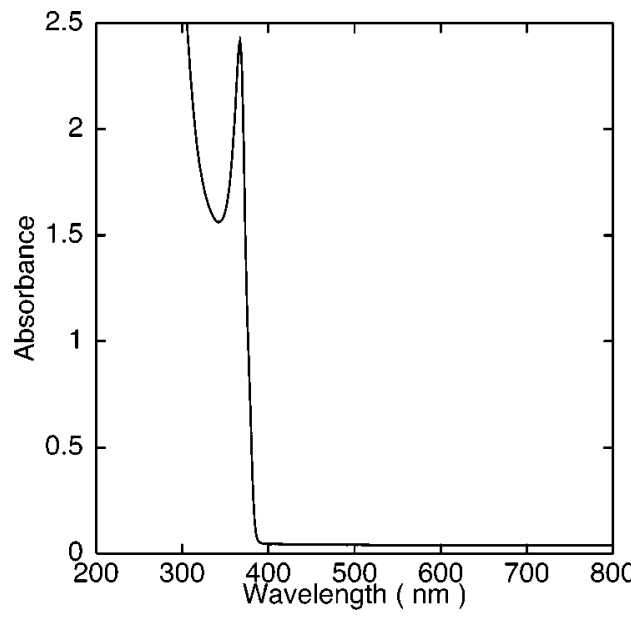

FIG. 1. Optical absorption spectra of glass sample.

The second-harmonic intensity of the poled glass samples was measured using the Maker fringe method. ${ }^{16}$ The setup for the SHG measurement is schematically illustrated in Fig. 2(a). The optical second-harmonic intensity was determined at room temperature using a pulsed $\mathrm{Nd}$ :YAG laser

(a)

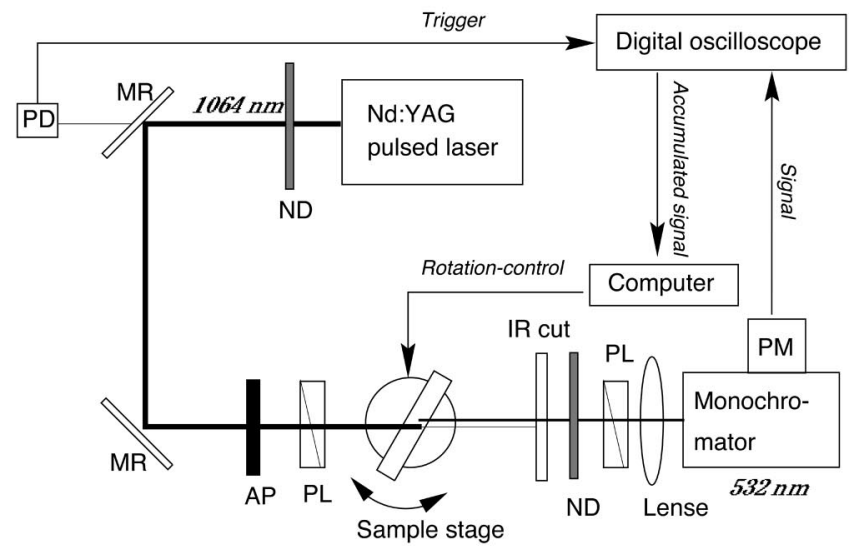

(b)

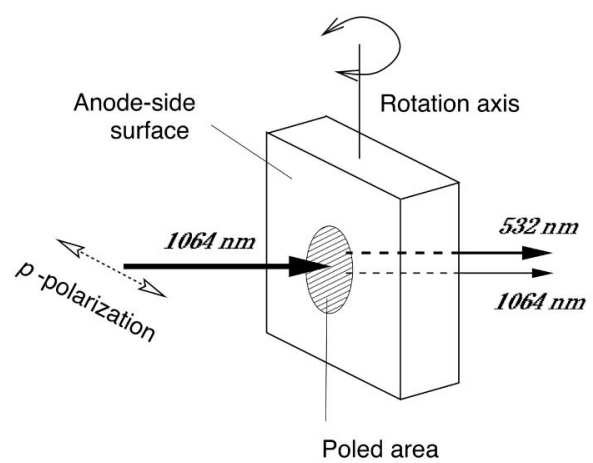

FIG. 2. (a) Schematic illustration of the experimental setup for the Maker fringe measurements. The second-harmonic wave is detected with a photomultiplier tube after elimination of the fundamental wave by using an IR-cut filter and a monochromator. The meanings of the abbreviations are as follows: ND: neutral density filter; MR: mirror; AP: aperture; PL: polarizer; IR cut: infrared-cut filter; and PM: photomultiplier. (b) Schematic illustration of the geometry of the laser incidence. The $p$-polarized fundamental wave is incident on the anode-side surface; the polarization is in the plane of incidence.
(Spectra Physics, GCR-11) which operated in a $Q$-switched mode with a $10 \mathrm{~Hz}$ repetition rate. The incident pulse was a p-polarized fundamental wave at $1064 \mathrm{~nm}$ with $9 \mathrm{~ns}$ duration. The $p$-polarized second-harmonic wave with $532 \mathrm{~nm}$ from the poled glass was passed through a monochromator (Spex, 270M) and detected with a photomultiplier (Hamamatsu Photonics, R955). The signal from the photomultiplier was accumulated by using a digital oscilloscope (Hewlett Packard 54522A). In order to perform the Maker fringe measurement the poled sample was rotated from $-70^{\circ}$ to $70^{\circ}$ on the $x$ axis, which is arranged parallel to the sample surface. The arrangement of the polarization of the incident wave and the rotation axis is shown in Fig. 2(b). For the determination of input light power, $Y$-cut quartz with a thickness of $1.046 \mathrm{~mm}$ and $d_{11}=0.34 \mathrm{pm} / \mathrm{V}$ was used as a reference under the condition of $p$ excitation and $p$ detection.

The refractive indices were measured for poled glass samples using an ellipsometer (Tokojiri, DVA-36VW). The wavelengths of the incident light were 1064 and $532 \mathrm{~nm}$.

\section{RESULTS}

Figure 1 shows optical absorption spectrum of the glass before poling. The absorption line seen at around $370 \mathrm{~nm}$ is the exciton peaks of $\mathrm{CuCl}$ nanocrystals precipitated by the heat treatment. ${ }^{15}$ The absorption band due to $\mathrm{Cu}^{+}$is observed at around 200-300 nm. ${ }^{17}$ No absorption band due to $\mathrm{Cu}^{2+}$ was observed. This suggests that copper is mainly present as $\mathrm{CuCl}$ or $\mathrm{Cu}^{+}$was dispersed in the glass network.

As for the nonpoled glass sample, no SHG was observed. After the poling, an opaque crystal layer composed of alkali chlorides, alkali silicates, and alkali borates was formed at the cathode-side surface. SHG measurements were carried out after removing the surface crystal layer ${ }^{18}$ since it did not contribute to the SHG.

Figure 3(a) shows the effect of surface etching on the $\mathrm{SH}$ intensity. In this case, the sample surface was mechanically etched by sandpaper and $\mathrm{CeO}_{2}$ powder. By $20 \mu \mathrm{m}$ etching of the cathode-side surface, the surface roughness caused by the formation of the crystal layer was removed and the SH intensity became larger. The intensity did not vary with further etching. As for the anode-side surface, the $10 \mu \mathrm{m}$ etching leads to a drastic decrease in SH intensity. A SH signal was not observed for more than $100 \mu \mathrm{m}$ etching. These results indicate that the SH signal is mainly generated from the anode-side surface.

On the other hand, for the sample after $20 \mu \mathrm{m}$ etching of the anode-side surface, further cathode-side etching brings about a decrease in SH intensity, as shown in Fig. 3(b); the SH intensity for the $400 \mu \mathrm{m}$ etching is about $40 \%$ of that for the 0 - $\mu \mathrm{m}$-etched sample. This indicates that the $\mathrm{SH}$ wave is generated from not only the anode-side surface but also the cathode-side surface. Similar results were observed in glass without heat treatment for the precipitation of $\mathrm{CuCl}$ nanocrystals.

Figure 4 shows the Maker fringe patterns of samples after cathode-side surface etchings of $0,10,60$, and $80 \mu \mathrm{m}$. By the $10 \mu \mathrm{m}$ etching, oscillation of the fringe pattern ap- 

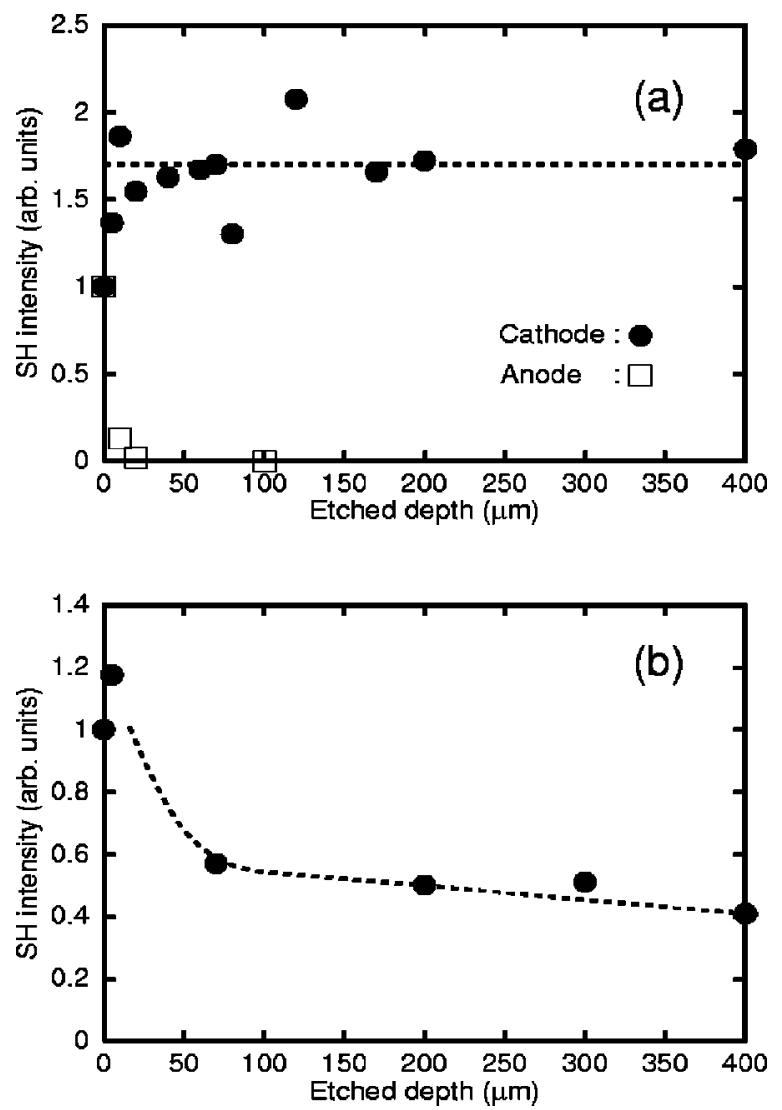

FIG. 3. Effects of (a) anode- and cathode-side surface etchings on the SH intensity and (b) cathode-side surface etching after $20 \mu \mathrm{m}$ etching of the anode-side surface on the SH intensity. The intensity is normalized so that the intensity of $0-\mu$ m-etched sample is unity.

pears. This oscillation is still observed for the $60-\mu$ m-etched sample, but disappears for $80 \mu \mathrm{m}$ etching.

The variation of the Maker fringe pattern with etch depth at the anode side is shown in Fig. 5. In this case, the oscillation is not observed for 0 - and $10-\mu$ m-etched samples, while a clear oscillation pattern is observed for the 20$\mu$ m-etched sample. Furthermore, a cathode-side surface etching was carried out for this sample. The variation of the Maker fringe pattern with cathode-side etch depth is shown in Fig. 6. As shown in Fig. 6, the oscillation is still observed after the $10 \mu \mathrm{m}$ etching of the cathode-side surface, but disappears for more than $70 \mu \mathrm{m}$ etching. The fringe pattern does not change even after $400 \mu \mathrm{m}$ etching.

\section{DISCUSSION}

As found from Fig. 3(a), the SH wave is mainly generated from the thin layer near the anode-side surface, although the result shown in Fig. 3(b) suggests that a nonlinear layer is also present at the cathode-side surface.

As shown in Fig. 5, since the magnitude of the nonlinearity at the cathode-side surface is much smaller than that of the anode-side surface, the oscillation is not observed in 0 or $10 \mu \mathrm{m}$ anode-side etched samples. By $20 \mu \mathrm{m}$ etching of anode-side surface, however, the amplitude of the SH wave generated from the anode-side surface decreases and is comparable with that of the anode-side surface, resulting in a

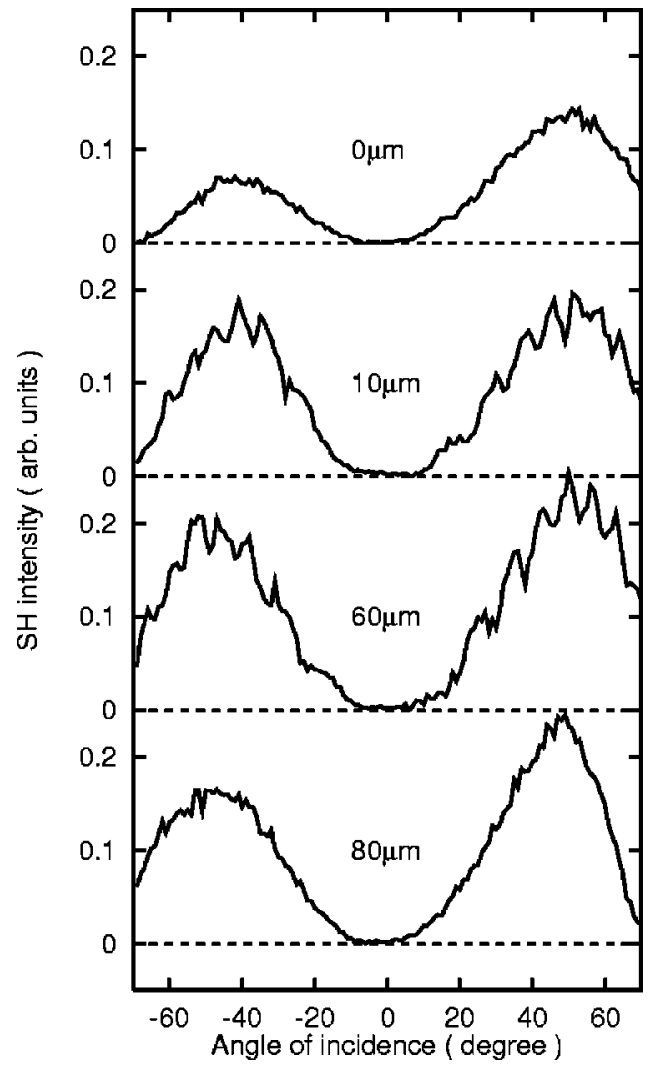

FIG. 4. Maker fringe patterns of the glass samples with cathode-side surface etchings of $0,10,60$, and $80 \mu \mathrm{m}$.

large oscillation. The etching of the cathode-side surface after the $20 \mu \mathrm{m}$ etching of the anode-side surface also causes a variation of the fringe pattern, as shown in Fig. 6. The oscillation is unambiguous for the $10-\mu \mathrm{m}$-etched sample, al-

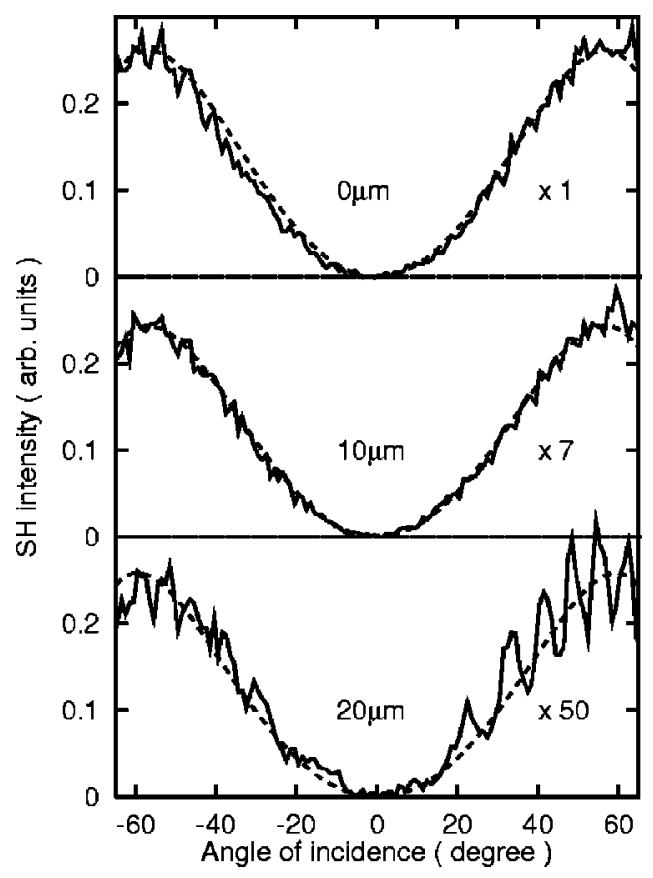

FIG. 5. Maker fringe patterns of the glass samples with anode-side surface etchings of 0,10 , and $20 \mu \mathrm{m}$. The dotted lines are the theoretical fringes drawn with the values shown in Tables I and II. 


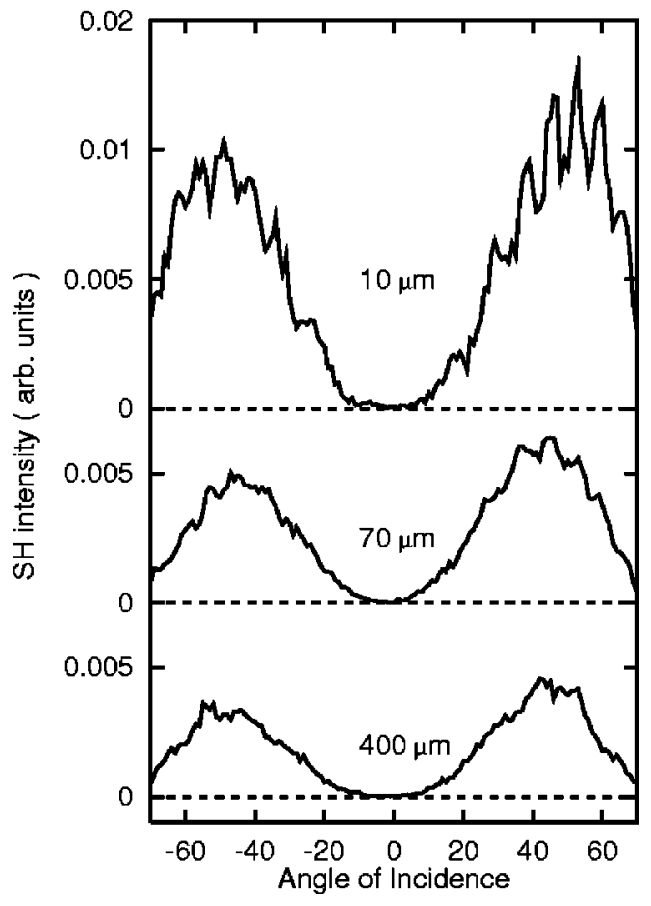

FIG. 6. Maker fringe patterns of the glass samples with cathode-side surface etchings of 10,70 , and $400 \mu \mathrm{m}$ after $20 \mu \mathrm{m}$ etching of the anode-side surface.

though the oscillation disappears when more than $70 \mu \mathrm{m}$ etching is carried out. This shows that the nonlinear layer thickness of the cathode-side surface is less than $70 \mu \mathrm{m}$, which is consistent with the value obtained from Fig. 4.

In order to estimate the second-order nonlinear susceptibility and nonlinear layer thickness, the experimental second-harmonic intensity was analyzed using the Maker fringe theory for poled glass. We assume that the poled glass has $C_{\infty_{v}}$ and Kleinman symmetry. ${ }^{19}$ In addition, we presuppose that the poled glass is described in terms of the isotropic dipole system. ${ }^{20}$ With these assumptions, the secondharmonic intensity is generally written as

$$
P_{2 \omega}=C d_{\mathrm{eff}}^{2} \mathrm{f}_{\omega}^{4} T_{2 \omega} R(\theta) P_{\omega}^{2}\left[1 /\left(n_{\omega}^{2}-n_{2 \omega}^{2}\right)^{2}\right] \sin ^{2} \Psi,
$$

where $P_{\omega}$ is the fundamental power, $d_{\text {eff }}$ is the SHG coefficient, $t_{\omega}$ and $T_{2 \omega}$ are the transmission factors, $R(\theta)$ is the multiple refraction factor, $C$ is a constant which depends on the beam area, and $\Psi$ is expressed by

$$
\Psi=(2 \pi L / \lambda)\left(n_{\omega} \cos \theta_{\omega}-n_{2 \omega} \cos \theta_{2 \omega}\right) .
$$

Here, $L$ is the length of the poled region, $\lambda$ is the wavelength of the fundamental wave, $\theta_{\omega}$ is the refraction angle for the

TABLE I. Refractive indices at the anode-side surface of poled and nonpoled glasses.

\begin{tabular}{lcc}
\hline \hline \multicolumn{1}{c}{ Glass } & $n_{532}$ & $n_{1064}$ \\
\hline Poled & 1.454 & 1.445 \\
Poled and $10 \mu \mathrm{m}$ etched & 1.488 & 1.473 \\
Poled and $20 \mu \mathrm{m}$ etched & 1.510 & 1.487 \\
Nonpoled & 1.518 & 1.501 \\
\hline \hline
\end{tabular}

TABLE II. Nonlinear layer thickness and SHG coefficient $d_{33}$ of glasses after etching. These values were derived by fitting the calculated Maker fringe pattern to experimental data.

\begin{tabular}{llll}
\hline \hline Etched depth $(\mu \mathrm{m})$ & \multicolumn{1}{c}{0} & \multicolumn{1}{c}{10} & \multicolumn{1}{c}{20} \\
\hline Nonlinear layer thickness $(\mathrm{mm})$ & 0.025 & 0.015 & 0.008 \\
$d_{33}\left(10^{-2} \mathrm{pm} / \mathrm{V}\right)$ & $1.89 \pm 0.05$ & $1.21 \pm 0.04$ & $0.65 \pm 0.05$ \\
\hline \hline
\end{tabular}

fundamental wave, and $\theta_{2 \omega}$ is the refraction angle for the second-harmonic wave. The effective SHG coefficient for $p, p$ polarization is written as

$$
\begin{aligned}
d_{\mathrm{eff}}= & 2 d_{31} \sin \theta_{\omega} \cos \theta_{\omega} \cos \theta_{2 \omega} \\
& +\left(d_{31} \cos ^{2} \theta_{\omega}+d_{33} \sin ^{2} \theta_{\omega}\right) \sin \theta_{2 \omega},
\end{aligned}
$$

where $3 d_{31}=d_{33}$.

The dotted lines shown in Fig. 5 are theoretical fringes. In this case, we assume that the SH wave is generated from only a thin layer near the anode-side surface. In the calculation, the refractive indices of the anode-side surface shown in Table I were used. The SHG coefficient and the thickness of the poled region thus obtained are summarized in Table II. As shown in Table II, the nonlinear layer thickness decreases with an increase of the etched depth, which is in accordance with the assumption that the SH wave is mainly generated from the anode-side surface. Therefore, in this case, we can regard the nonlinear layer thickness as the length of the poled region near the anode-side surface. The theoretical curves are in good agreement with the experimental fringes for $0-$ and $10-\mu \mathrm{m}$-etched samples, although the oscillation seen in the experimental fringe for the $20-\mu$ m-etched sample is not reproduced. On the other hand, as shown in Fig. 7, the theoretical fringe drawn with the nonlinear layer thickness, $L=0.81 \mathrm{~mm}$, can reproduce the oscillation. The value of $0.81 \mathrm{~mm}$ corresponds to the sample thickness. In addition,

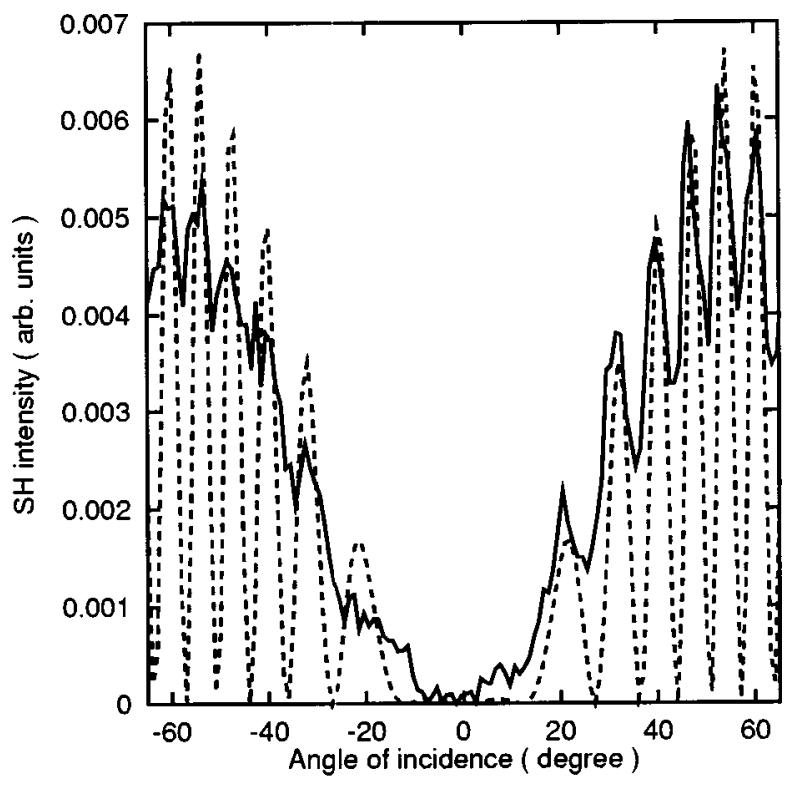

FIG. 7. Maker fringe pattern of the glass sample with $20 \mu \mathrm{m}$ etching of the anode-side surface. The dotted line is the theoretical fringe drawn with $L$ $=0.81 \mathrm{~mm}, d_{33}=6.5 \times 10^{-3} \mathrm{pm} / \mathrm{V}, n_{532}=1.510$, and $n_{1064}=1.487$. 
the oscillation found in Figs. 4 and 6 arises from the interference between $\mathrm{SH}$ waves generated from the layers, the thickness of which is the same for each. These results are in accordance with the conclusion that the nonlinear layer is also present at the cathode-side surface and the oscillation originates from the interference between $\mathrm{SH}$ waves generated from anode- and cathode-side surfaces.

Procter and Sutton reported that the potential drop is larger near the anode-side surface than the cathode side under such a condition that only cations can migrate in glass. ${ }^{21}$ As shown in Table II, the SHG coefficient $d_{33}$ decreases with an increase of the etched depth. This variation is similar to the depth dependence of the voltage. ${ }^{21}$

As for the poled silica glasses, the initial stage of poling is the migration of cations such as $\mathrm{Na}^{+}$, as suggested by Myers, Mukherjee, and Brueck. ${ }^{1}$ The migration of cations leaves a thin space-charge layer near the anode-side surface, and the external voltage drops significantly in this region. In other words, a large electric field is applied to the thin layer in the glass near the anode. This large electric field is frozen in the anode-side surface region of the glass, leading to the second-harmonic generation. From this point of view, in our previous work, ${ }^{18}$ the origin of the nonlinear layer near the anode-side surface was attributed to the migration of $\mathrm{Cu}^{+}$. Similarly, it is suggested that the nonlinear layer near the cathode-side surface originates from the migration of $\mathrm{Cl}^{-}$. These are supported by the results that the $\mathrm{SH}$ wave is mainly generated from the anode-side surface and that the nonlinear layer was present at both surfaces in the case of glass without precipitation of $\mathrm{CuCl}$ nanocrystal.

Considering the presence of $\mathrm{CuCl}$ nanocrystals in glass, the possibility of $\mathrm{SHG}$ from $\mathrm{CuCl}$ nanocrystals still remains. It was reported that the melting point of $\mathrm{CuCl}$ nanocrystal is about $300{ }^{\circ} \mathrm{C}$ (Ref. 22) and $\mathrm{CuCl}$ crystal shows piezoelectricity. ${ }^{23}$ If the strain of the crystal structure is induced by the poling at around the melting point and frozen at room temperature, the optical anisotropy of $\mathrm{CuCl}$ would increase. However, this possibility was not confirmed because of the small concentration of $\mathrm{CuCl}$ in glass. At this moment, considering that no SHG was detected in the case of the nonpoled glass sample, the contribution of the $\mathrm{CuCl}$ nanocrystals would be very small. Hence, the main origin for the SHG is attributable to the migration of $\mathrm{Cu}^{+}$and $\mathrm{Cl}^{-}$.

\section{CONCLUSION}

The second-harmonic intensity was measured using the Maker fringe method for electrically/thermally poled borosilicate glasses containing $\mathrm{CuCl}$. The effect of surface etching on the SH intensity and the Maker fringe pattern was investigated. The results indicate that a nonlinear layer is present at both surfaces, although analysis of the experimental Maker fringe patterns reveals that the SH wave is mainly generated from the thin layer near the anode-side surface. In fact, oscillations in fringe patterns originating from interference of SH waves generated from both surfaces were observed. In this case, the origin of the formation of these nonlinear layers is attributable to the migration of $\mathrm{Cu}^{+}$and $\mathrm{Cl}^{-}$ ions by poling.

\section{ACKNOWLEDGMENTS}

The authors are grateful to Naoki Sugimoto of Asahi Glass Co., Ltd. for sample preparation and Professor T. Yoko of the Institute for Chemical Research, Kyoto University for measurements of the refractive index.

${ }^{1}$ R. A. Myers, N. Mukherjee, and S. R. J. Brueck, Opt. Lett. 16, 1732 (1991).

${ }^{2}$ H. Nasu, H. Okamoto, A. Mito, J. Matsuoka, and K. Kamiya, Jpn. J. Appl. Phys., Part 2 32, L406 (1993).

${ }^{3}$ H. Nasu, H. Okamoto, K. Kurachi, J. Matsuoka, and K. Kamiya, J. Opt. Soc. Am. B 12, 644 (1995).

${ }^{4}$ H. Imai, S. Horinouchi, N. Asanuma, K. Fukao, D. Matsuki, H. Hirashima, and K. Sasaki, J. Appl. Phys. 84, 5415 (1998).

${ }^{5}$ H. G. Kim, T. Komatsu, K. Shioya, K. Matushita, K. Tanaka, and K. Hirao, J. Non-Cryst. Solids 208, 303 (1996).

${ }^{6}$ Y. B. Kao, Y. Hu, H. Aheng, J. D. Mackenzie, K. Perry, G. Bourhill, and J. W. Perry, J. Non-Cryst. Solids 167, 247 (1994).

${ }^{7}$ K. Tanaka, H. Kuroda, K. Hirao, and N. Soga, Mater. Res. Soc. Symp. Proc. 453, 271 (1997).

${ }^{8}$ Y. Ding, A. Osaka, and Y. Miura, J. Am. Ceram. Soc. 77, 749 (1994).

${ }^{9}$ See, for example, T. Tsuchiya and H. Yamakawa, J. Ceram. Soc. Jpn. 106, 415 (1998); N. Machida, Y. Shinkuma, and T. Minami, Solid State Ionics 45, 123 (1991).

${ }^{10}$ R. C. Miller and W. A. Nordland, Phys. Rev. B 2, 4896 (1970).

${ }^{11}$ D. C. Haueisen and H. Mahr, Phys. Rev. B 8, 2969 (1973).

${ }^{12}$ D. Chemla, P. Kupecek, C. Schwartz, C. Schwab, and A. Goltzene, IEEE J. Quantum Electron. QE-7, 126 (1971).

${ }^{13}$ R. C. Miller, S. C. Abrahams, R. L. Barns, J. L. Bemstein, and W. A. Nordland, Solid State Commun. 9, 1463 (1971).

${ }^{14}$ O. A. Aktsipetrov, P. V. Elyutin, A. A. Fedyanin, A. A. Nikulin, and A. N. Rubtsov, Surf. Sci. 325, 343 (1995).

${ }^{15}$ N. Sugimoto, T. Manabe, and S. Ito, Reports Res. Lab., Asahi Glass, 42, 21 (1992)

${ }^{16}$ P. D. Maker, R. W. Terhune, M. Nisenoff, and C. M. Savage, Phys. Rev. Lett. 8, 21 (1962).

${ }^{17}$ Y. Fujimoto and M. Nakatsuka, J. Lumin. 75, 213 (1997).

${ }^{18}$ J. Sasai, K. Tanaka, and K. Hirao, in Proceedings of the 16th International Japan-Korea Seminar on Ceramics, The Organizing Committee of IJKSC (The Organizing Committee of IJKSC, Okayama, Japan, 1999), p. 167.

${ }^{19}$ D. A. Kleinman, Phys. Rev. 126, 1977 (1962).

${ }^{20}$ K. D. Singer, M. K. Kuzyk, and J. E. Sohn, J. Opt. Soc. Am. B 4, 968 (1987).

${ }^{21}$ T. M. Proctor and P. M. Sutton, J. Am. Ceram. Soc. 43, 173 (1960).

${ }^{22}$ A. Ekimov, J. Lumin. 70, 1 (1996).

${ }^{23}$ J. C. Phillips, Bonds and Bonds in Semiconductors (Academic, New York, 1973). 